\title{
Comparison of measured and modelled wetness duration as inputs to a grape disease model
}

\author{
W.R. Henshall, G.N. Hill and R.M. Beresford \\ The New Zealand Institute for Plant \& Food Research Ltd, Private Bag 92-169, \\ Auckland, New Zealand \\ Corresponding author: gareth.hill@plantandfood.co.nz
}

\begin{abstract}
Measured surface wetness duration is often used in disease risk prediction models, but is only available from a few weather stations. Wetness can be modelled from more widely available weather station networks using other meteorological variables. This study compared wetness duration measured using different methods of interpreting wetness sensor output, and from different sensor types, with wetness calculated from a classification and regression tree (CART) model. The model calculated wetness from temperature, relative humidity and wind speed. Different wetness sensors and different wetness calculation methods from the same sensor made little difference to recorded wetness duration. Total wetness duration was greater for modelled than for measured wetness at all but one of seven sites investigated. The use of modelled and measured wetness inputs into a grape botrytis prediction model indicated that modelled wetness is unsuitable for use in New Zealand without being calibrated for local conditions.
\end{abstract}

Keywords wetness duration, grape, botrytis, modelling.

\section{INTRODUCTION}

Surface wetness duration is important for plant disease development and is often incorporated into plant disease risk models. Although various types of electrical sensors to measure surface wetness have long been available, there are problems associated with wetness measurement, including a lack of standardisation in sensor types, a lack of protocols for interpreting wetness and variation in output between individual sensors (Henshall et al. 2005). Because wetness duration is not a standard variable recognised by the World Meteorological Organisation (WMO), deployment of wetness sensors is generally confined to specific weather stations set up for disease risk prediction (Rowlandson et al. 2015). To utilise data from widely available WMO standard weather stations, models have been developed to estimate surface wetness from other meteorological variables. These models can be broadly classified as empirical, derived from statistical correlations between observed wetness and various inputs, or physical, derived from energy balance equations. One type of empirical model is the classification and regression tree (CART) model, requiring temperature, relative humidity and wind speed - all standard WMO variables - and dew point derived from temperature and relative humidity (Kim et al. 2002).

The botrytis decision support (BDS) system uses a network of weather stations in New 
Zealand wine production regions to predict the likelihood that vineyards will be severely affected by botrytis bunch rot (Botrytis cinerea) at harvest time. The BDS system includes an 'early-season model', which, during the period between grape flowering and the beginning of ripening, predicts the risk of a major botrytis epidemic ( $\geq 3 \%$ severity) at harvest (Beresford et al. 2012). The early-season model incorporates the 'Bacchus' risk index, which uses wetness duration measured at mast height (1.5 $\mathrm{m}$ above ground) and temperature (Kim et al. 2007). Because wetness sensors are not available in some regions where the BDS system could be implemented, the possibility of using the CART model to replace wetness measurements was investigated.

The objectives of the study were to: (1) compare three methods for calculating whether an hour is wet or dry from the output of a single electrical resistance sensor, (2) compare estimates of wetness duration using the CART model and three different types of wetness sensor (two electrical resistance types and one dielectric constant type), (3) determine whether wetness duration estimated by the CART model and standard flat plate resistance sensors is consistent across geographic regions and (4) determine whether the CART model and flat plate resistance sensors give similar disease risk predictions using the BDS early-season model.

\section{MATERIALS AND METHODS}

All statistical analyses were performed using RStudio (version 0.98; RStudio, Inc., Boston, MA, USA; R version 3.0.1).

\section{Comparison of methods for calculating wetness}

Three different methods for calculating whether or not an hour is wet were compared for a single flat plate electrical resistance wetness sensor ('237-L'; Campbell Scientific Instruments, UT, USA; Gillespie \& Kidd 1978). The sensor was mounted on a mast $1.5 \mathrm{~m}$ above ground at the Plant \& Food Research weather station at Pukekohe $\left(37.210^{\circ} \mathrm{S}, 174.862^{\circ} \mathrm{E}\right)$. The weather station was on grass, $10 \mathrm{~m}$ from the edge of a vineyard block. Data were collected from
18 February to 14 April 2015 using $1 \mathrm{~min}$ sensor scans and a 15 min output interval from the data logger (CR10; Campbell Scientific Instruments). The three estimation methods were: mean percentage wetness, time fraction wet as calculated by the data logger program $\left(\mathrm{TFW}_{\mathrm{P}}\right)$ and time fraction wet calculated from the raw resistance values output by the sensor $\left(\mathrm{TFW}_{\mathrm{R}}\right)$.

Mean percentage wetness from a 237-L sensor is the standard measure of wetness used in New Zealand for disease forecasting models (Beresford \& Spink 1992), including the BDS early-season model. The datalogger output values are scaled from 0 to 100 and if the mean value over the output interval is $\geq 50$, then the interval is considered wet. $\mathrm{TFW}_{\mathrm{P}}$ is calculated by the data logger program and is output every $15 \mathrm{~min}$ as a value between 0 (interval completely dry) and 1 (interval completely wet). Mean resistance across the 237-L sensor was also output every $15 \mathrm{~min}$ and ranged from $0 \mathrm{k} \Omega$ when wet to $6999 \mathrm{k} \Omega$, effectively infinite, when dry. If the mean resistance was between 0 and $150 \mathrm{k} \Omega$, that output interval was given a TFW $\mathrm{R}_{\mathrm{R}}$ reading of 1 ; if the mean resistance was over $150 \mathrm{k} \Omega$, the interval was given a reading of 0 . For both time fraction wet calculations, the four $15 \mathrm{~min}$ readings were averaged for each hour and the hour was considered wet if $\geq 0.5$.

\section{Wetness duration estimated by three sensor types and the CART model}

Two 237-L sensors, two cylindrical electrical resistance sensors (Young et al. 1979), and one leaf-shaped painted sensor of the dielectric constant type ('LWS'; Decagon Devices, WA, USA) were deployed on the Pukekohe weather station mast. Within the bunch line of a Vitis vinifera L. 'Sauvignon blanc' grape canopy there were two sensors of each of the three types. Separate data loggers on the mast and in the canopy scanned sensors every $1 \mathrm{~min}$ and logged the mean reading every $15 \mathrm{~min}$. Total number of wet hours per day (midday to midday) was calculated for each sensor type from 13 November 2014 to 31 March 2015.

An hour was considered wet if the mean output value from a particular sensor reached 
a particular threshold. Output values from the 237-L and cylindrical sensors were scaled ratios, while outputs from the LWS sensors were in units of $\mathrm{mV}$. The threshold for the $237-\mathrm{L}$ sensor was 50 , as described above. The cylindrical sensors all gave a minimum of 0 , with a maximum varying from 83 to 98 . The LWS sensors gave minima between 157 and $179 \mathrm{mV}$ and maxima between 682 and $1008 \mathrm{mV}$. As no standard threshold was available for the cylindrical or LWS sensors, the threshold was set as the median value across all 15 min readings. Median values ranged from 1 to 4 for cylindrical sensors and 265 to 268 for LWS sensors. The 237-L sensors were also tested to see if this was a more sensor-specific method of setting the threshold than a $\geq 50$ standard. The $237-\mathrm{L}$ sensors all gave minima of zero, with maxima ranging from 100 to 113 and median values ranging from 7 to 34 .

The CART model was used to predict wetness duration as described by Kim et al. (2002), with the exception that if rain occurred in an hour, it was considered wet regardless of the output from the CART model. Because the CART equations included the square root of temperature, calculations were limited to a growing season from 1 October to 31 March to exclude temperatures less than zero as far as possible. On the few occasions when frosts did occur, subzero air temperatures were set to zero if above $-0.5^{\circ} \mathrm{C}$. For lower air temperatures, the CART calculations were estimated from results for the preceding and following hours.

\section{Wetness duration at seven sites estimated by CART and 237-L sensor}

Hourly data were obtained from Metwatch Online (HortPlus, 2015) for weather stations at Plant \& Food Research orchards at Kerikeri $\left(35.179^{\circ} \mathrm{S}\right.$, $\left.173.930^{\circ} \mathrm{E}\right)$, Te Puke $\left(37.823^{\circ} \mathrm{S}, 176.321^{\circ} \mathrm{E}\right)$, Havelock North $\left(39.655^{\circ} \mathrm{S}, 176.876^{\circ} \mathrm{E}\right)$, Riwaka $\left(41.096^{\circ} \mathrm{S}, 171.972^{\circ} \mathrm{E}\right), \quad$ Blenheim $\left(41.497^{\circ} \mathrm{S}\right.$, $\left.173.963^{\circ} \mathrm{E}\right)$ and Clyde $\left(45.206^{\circ} \mathrm{S}, 169.315^{\circ} \mathrm{E}\right)$. Although the two northern sites are not in major grape growing regions, they were included to provide a range of climatic conditions. All sites included flat plate 237-L wetness sensors, as well as standard WMO meteorological sensors.
Relevant weather variables were entered into a spreadsheet for calculation of CART wetness at hourly intervals. Three growing seasons, 2012-13, 2013-14 and 2014-15, were included in the study.

\section{BDS model predictions using CART and 237-L sensor}

The BDS model was run for three sites located in grape growing areas (Havelock North, Blenheim and Clyde) using wetness duration measured by a 237-L sensor, with a wetness threshold of 50, and wetness duration calculated from the CART model.

\section{RESULTS}

\section{Method of calculating wetness duration}

Wetness duration calculated from a single sensor at Pukekohe by three different methods all produced similar results (Figure 1). Mean daily wetness durations for each method were not significantly different $(\mathrm{P}>0.05)$.

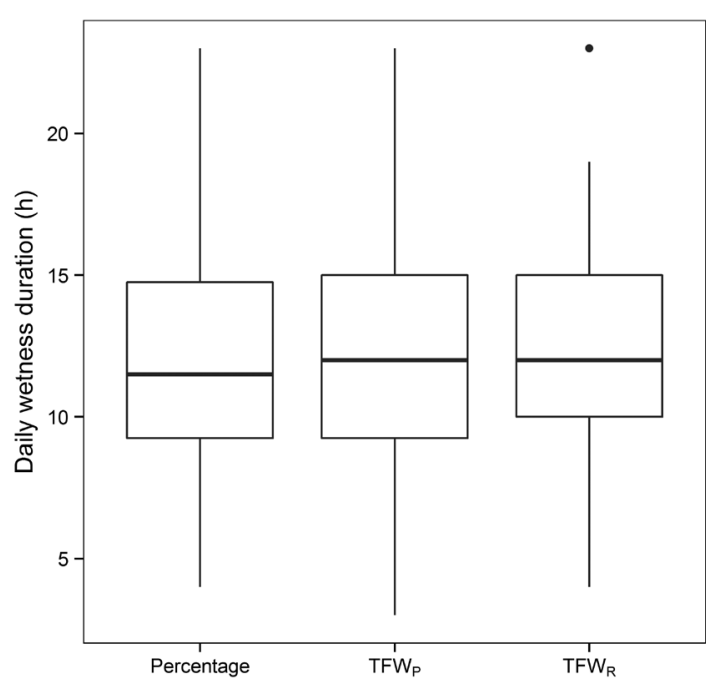

Figure 1 Daily wetness duration measured by a single 237-L sensor using three methods for determining whether an hour is wet or dry: (1) mean hourly percentage wetness (Percentage), (2) time fraction wet, as calculated by logger program $\left(\mathrm{TFW}_{\mathrm{P}}\right)$, and (3) time fraction wet calculated from resistance values $\left(\mathrm{TFW}_{\mathrm{R}}\right)$. Boxes represent lower quartile, median and upper quartile. 


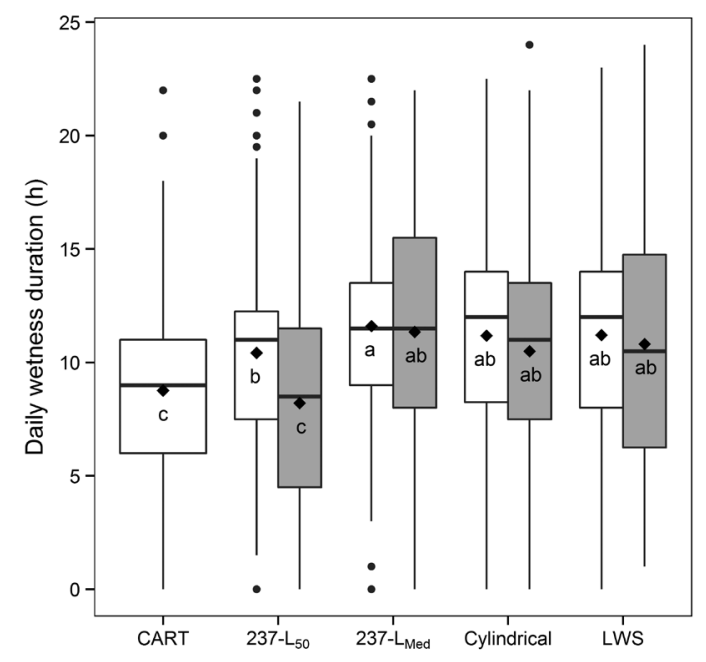

Wetness duration estimated by three sensor types and the CART model

The CART model gave a significantly lower estimation of daily wetness duration than the sensors, except for the within-canopy 237-L with a wetness threshold of 50 (Figure 2). Wetness duration was significantly lower $(\mathrm{P}<0.05)$ when measured in the canopy by the $237-\mathrm{L}$ sensor using a wetness threshold of 50, but was not the case for the canopy cylindrical or LWS sensors (Figure 2). However, when the median values of the 237-L sensors were used as threshold values, there was no significant difference between wetness duration measured outside and inside the canopy.

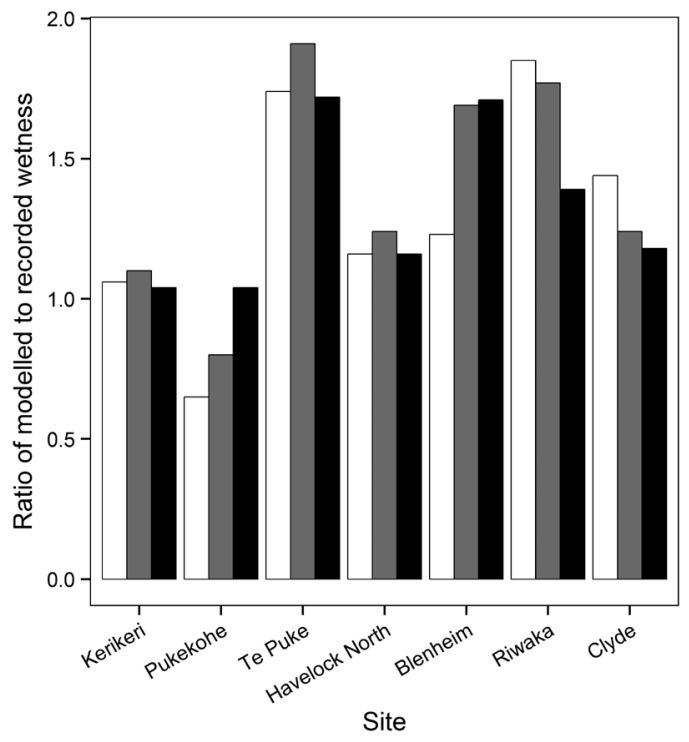

Figure 2 Daily wetness duration predicted by the classification and regression tree (CART) model compared with three wetness sensor types both outside (white) and inside (grey) the grape canopy. Data shown for 237-L using a wetness threshold of $50\left(237-\mathrm{L}_{50}\right)$ and the median value for the sensor $\left(237-\mathrm{L}_{\mathrm{Med}}\right)$. Daily wetness duration was averaged across two sensors prior to analysis, with the exception of a single LWS sensor outside the canopy. Boxes represent lower quartile, median and upper quartile. Diamonds represent mean daily wetness duration; means with the same letter are not significantly different $(\mathrm{P}>0.05)$.

Wetness duration at seven sites estimated by CART and 237-L sensor

The ratio of modelled hours wet to recorded hours wet varied considerably between sites, and to a lesser extent between seasons (Figure 3). For most sites across the three seasons the CART model overestimated wetness, but at Pukekohe the model underestimated wetness for two of the three seasons.

BDS model predictions using CART and 237-L sensor

As could be expected from the ratios above, botrytis risk calculated from CART modelled wetness was generally greater than that calculated from measured wetness. Despite this, there was agreement in early season epidemics predicted from measured and modelled wetness at Havelock North and Clyde over the three seasons (Table 1). However, at Blenheim the differences between measured and modelled wetness led to a complete lack of agreement in BDS output.

Figure 3 Ratio of wetness duration modelled using the classification and regression tree (CART) to wetness duration recorded using a 237-L sensor at seven sites over three seasons: 2012-13 (white), 2013-14 (grey) and 2014-15 (black). 


\section{DISCUSSION}

This study sought to compare various approaches to surface wetness measurement to determine how altering the methodology affected the outcomes of a disease model.

The comparison of different sensor types on a mast adjacent to the grape canopy and within the canopy itself at Pukekohe produced similar results to a previous study for the 237-L sensor with a threshold of 50 (Henshall et al. 2005). The shorter wetness durations within the canopy for the 237-L sensor, compared with those recorded outside, probably reflect different radiation environments. The same is probably true for the LWS sensors with canopy sensors recording fewer wet hours than the one outside, although the difference was not significant. The cylindrical sensors, able to radiate in all directions, are less affected by shelter and hence record similar wetness durations inside and outside the canopy. The use of median values for all sensors resulted in similar measurements across all sensor types. Although this may be an effect of the particular weather conditions at the Pukekohe site during the 2014-15 season, it would be worth considering using the median method of determining wetness threshold for 237-L sensors, rather than the current standard of $50 \%$. The readings from 237-L sensors tend to change over time and the median method would allow the threshold to be adjusted accordingly and potentially automatically through the data logger program.

The site dependence of the CART model reflects the fact that the model was developed in mid-west USA, and requires recalibration for New Zealand conditions. The unpainted flat plate wetness sensors (237-L) used in the seasonal study are known to show considerable individual variation in output (Henshall et al. 2003), so the observed inter-site differences could include measured as well as modelled variation. At Pukekohe, underestimation of wetness duration by the CART model, compared with overestimation at other sites, may have arisen because the wetness sensors were in the sheltered grape block, whereas at the other sites all sensors were on or adjacent to the WMO standard weather mast. Different sensors and different methods of calculating wetness from the same sensor were found to produce very similar wetness estimates, so any of the sensor types and wetness calculations tested in this study would be adequate for use in current wetness-based disease models. When applied to the BDS system, the shortcomings of the CART model appeared inconsequential in Havelock North (major epidemic most years) and Clyde (no epidemic most years). However, measured and modelled wetness led to opposite predictions of the severity of botrytis epidemics in Blenheim, where conditions tend to be more variable, so the model remains unsuitable for New Zealand use without modification.

Table 1 Botrytis decision support prediction of early season epidemic using wetness duration measured by a 237-L sensor (measured wetness) and modelled by the classification and regression tree (modelled wetness).

\begin{tabular}{lllll}
\hline Site & Season & Measured wetness & Modelled wetness & Agreement \\
\hline Havelock North & $2012-13$ & Major & Major & + \\
& $2013-14$ & Major & Major & + \\
& $2014-15$ & Major & Major & + \\
\hline Blenheim & $2012-13$ & Minor & Major & - \\
& $2013-14$ & Minor & Major & - \\
& $2014-15$ & Minor & Major & - \\
\hline Clyde & $2012-13$ & Minor & Minor & + \\
& $2013-14$ & Minor & Minor & + \\
& $2014-15$ & Minor & Minor & + \\
\hline
\end{tabular}




\section{ACKNOWLEDGEMENTS}

We would like to thank Peter Wright and Moe Jeram (Plant \& Food Research) for maintaining the grape block throughout the trial.

\section{REFERENCES}

Beresford RM, Spink M 1992. A national disease forecasting system for apple black spot (Venturia inaequalis) in New Zealand. Acta Horticulturae 313: 285-296.

Beresford RM, Evans K, Hill GN 2012. Botrytis decision support: online tools for predicting seasonal risk of botrytis bunch rot. Wine \& Viticulture Journal September/October 2012: 46-52.

Gillespie TJ, Kidd GE 1978. Sensing duration of leaf moisture retention using electrical impedance grids. Canadian Journal of Plant Science 58: 179-187.

Henshall WR, Beresford RM, Chynoweth RW 2003. Does variability in grape canopy wetness affect infection period calculations? 8th International Congress of Plant Pathology, Christchurch, New Zealand. Volume 2 (Abstracts of offered papers): 110.
Henshall WR, Beresford RM, Chynoweth RW, Ramankutty P 2005. Comparing surface wetness inside and outside grape canopies for region-wide assessment of plant disease risk. New Zealand Plant Protection 58: 80-83.

Hortplus 2015. Weather stations hourly. http:// hortplus.metwatch.co.nz (accessed 15 April 2015).

Kim KS, Taylor SE, Gleason ML, Koehler KJ 2002. Model to enhance site-specific estimation of leaf wetness duration. Plant Disease 86: 179-185.

Kim KS, Beresford RM, Henshall WR 2007. Prediction of disease risk using site-specific estimates of weather variables. New Zealand Plant Protection 60: 128-132.

Rowlandson T, Gleason M, Sentelhas $\mathrm{P}$, Gillespie T, Thomas C, Hornbuckle B 2015. Reconsidering leaf wetness duration determination for plant disease management. Plant Disease 99(3): 310-319.

Young K, Galbreath NH, Hewett EW 1979. A system of regulating sprinkling during evaporative cooling of apple buds to delay bloom. Journal of Agricultural and Engineering Research 24: 209-13. 